\title{
Simple schizophrenia: case report and review of the literature
}

\author{
Sofia Efstratiou ${ }^{1,2^{*}}$, Nikolaos Tzavaras ${ }^{3}$ \\ From $1^{\text {st }}$ International Congress on Neurobiology and Clinical Psychopharmacology and European \\ Psychiatric Association Conference on Treatment Guidance \\ Thessaloniki, Greece. 19-22 November 2009
}

\section{Background}

Simple schizophrenia remains controversial. In this study we illustrate the diagnostic complexities of the disorder by emphasizing the importance of the criterion "progressive development of odd behaviour".

\section{Materials and methods}

We report the case of a 35-year-old man with "organic mental disorder". His medical and psychiatric history notes were peer reviewed and, neuropsychological assessments (WISC and Rorschach), blood tests, EEG and Computed tomography were carried out. Several psychiatric scales (SCID, BPRS, HDS-17, CAS and GAF and MMSE) were also used to establish diagnosis and to evaluate treatment changes. We reviewed the differential diagnosis of the case, the history of simple schizophrenia and its importance both to this case and to current thought about schizophrenia.

\section{Results}

The patient had followed a social skills training program in a community setting for two years. His current state indicates IQ: 97, attention and concentration deficits, blunting of affect, inability to meet the demands of society and decline in overall performance (GAF: 41-50, CAS: 25). Neuroimaging and laboratory tests are normal. Furthermore he meets research criteria for simple deteriorative disorder or simple schizophrenia. He is been treated with aripiprazole now, with good response.

\section{Conclusions}

The review of the literature (historical articles, case reports, epidemiological and trancultural surveys, studies on reliability and validity and review articles) demonstrates the heterogeneity of the simple schizophrenia diagnosis oven the years. However there is a lack of developmental and psychopathological approaches that could provide a better understanding on the disorder. More case reports may contribute to that.

\section{Author details}

'Department of Psychiatry, General Hospital of Kilkis, NHS, Greece. ${ }^{2}$ University of Thrace, Greece. ${ }^{3}$ Hellenic Psychiatric Association, Greece.

Published: 22 April 2010

\section{References}

1. Suzuki M, Nohara S, Hagino H, Takahashi T, Kawasaki Y, Yamashita I, Watanabe N, Seto H, Kurachi M: Prefrontal abnormalities in patients with simple schizophrenia: structural and functional brain-imaging studies in five cases. Psychiatry Res 2005, 140(2):157-71, Epub 2005 Oct 21.

2. Serra-Mestres J, Gregory CA, Tandon S, Stansfield AJ, Kemp PM, McKenna PJ: Simple schizophrenia revisited: a clinical, neuropsychological, and neuroimaging analysis of nine cases. Schizophr Bull 2000, 26(2):479-93.

3. Black DW, Boffeli TJ: Simple schizophrenia: past, present, and future. Am J Psychiatry 1989, 146(10):1267-73.

4. Mack AH, Feldman JJ, Tsuang MT: A case of "pfropfschizophrenia": Kraepelin's bridge between neurodegenerative and neurodevelopmental conceptions of schizophrenia. Am J Psychiatry 2002, 159(7):1104-10.

doi:10.1186/1744-859X-9-S1-S183

Cite this article as: Efstratiou and Tzavaras: Simple schizophrenia: case report and review of the literature. Annals of General Psychiatry 2010 9(Suppl 1):S183.

'Department of Psychiatry, General Hospital of Kilkis, NHS, Greece 